Geomatics, Landmanagement and Landscape No. 3 • 2018, 45-54

\title{
PRINCIPLES OF IMPULSE MODELING OF LOCAL CLUSTERS
}

\author{
Andriy Pavliv
}

\section{Summary}

The perspective of urban fabric transformation is formulated in connection with the reduction of the influence of industrial factors and the development of information-rich society. This tendency transforms large functional areas of the industrial city into local residential clusters with a pedestrian accessibility of up to $2 \mathrm{~km}$. The aggregate of such clusters of universal pedestrian accessibility ("urban villages"), which is superimposed by the growth of local self-organization and vertical initiatives, may cause partial revision of the functions of city-wide management. A key element for the practical implementation of the impulse development strategy of the city in the 21 st century is the prediction of the development of a basic urban unit in a post-industrial city, which in this work is called the local cluster. The phenomenon of impulse development of urban fabric is analysed, and the system of laws and principles that transform urban complexes into post-industrial ones is outlined. It has been found that the impulse strategy, in contemporary conditions, should be made of two components and contain both city-wide and local levels of management and modeling. The level of local clusters, which is being discussed herein, involves the presence of a combination of impulse factors, the content and names of which are presented in this work.

\section{Keywords}

impulse strategy $\bullet$ urban unit of the post-industrial city $\bullet$ techno-biospheric symbiosis $\bullet$ living space of a wide choice

\section{Introduction}

Impulse strategy is a multi-stage combination of factors that involves the creation of a residential local cluster (a fundamental urban unit in a post-industrial city), within which the widest possible choice is combined with the closest possible accessibility. These units create an immediate living environment of a city dweller, and they provide material for evaluation, based on which one can determine the level of quality of an urban formation. The idealistic hypothesis of such a concept involves endless choice in the absence of any distance to its implementation. The realistic hypothesis implies a fixed distance of the pedestrian accessibility in the form of a conditional circle of 2 kilometres in diameter, which is characterized by the continuous, ongoing process of saturation 
with the possibilities of choice. The category of impulse factors that are realized at this level include: techno-biospheric symbiosis and a living space of a wide choice.

\section{Material and methods}

The spontaneous nature of the emergence and implementation of the ideas associated with the system of small self-sufficient residential clusters testifies to the procedural differences between modernist models of management and design of the urban environment versus the horizontal initiatives that arise as a result of the activities by local communities. In addition, this gap often coincides with the difference in approaches to the functional settlement of the modern era, and the settlement of the post-industrial period defined by the category of sustainability. This is particularly the case in two important monographs: G. Bramley and S. Power "Urban Form and Social Sustainability" and P. Hall "Urban and Regional Planning" [Bramley and Power 2009, Hall 2005].

The "affordability-choice" urban development potential is increasingly acquiring a "wider choice" structure, and forcing the surrounding areas to be transformed towards the "mixed use" principle, which is relevant to it [Register 1987, Cherkes 1992].

In the modern city-planning theory, the fact of diversity in conditions of close concentration (density) is considered one of the main tasks of urban science in the twenty-first century. This was particularly the case in the work of M. Gendelsonas, "X-Urbanism: Architecture and the American City", published by Harvard University Press [Gandelsonas 1999], the monograph by E. Glaeser "The triumph of the City" [Glaeser 2011], a well-known study of 1995 by R. Koolhaas and B. Mau "S, M, L, XL" [Koolhaas and Mau 1995], S. Kostof "The City Shaped" [Kostof 1999], M. Neuman "The Compact City Fallacy" [Neuman 2005], and a number of other works. Given that pedestrian accessibility is associated with such parameters as average speed of walking, which is $4 \mathrm{~km}$ per hour, and the standard time frames that we use to calculate the proximity of such objects as a public transport stop, which is 15 minutes, it can be assumed that the maximum diameter of such a zone should be 2000 meters [Sverdlin 2004].

\section{Results and discussion}

The level of local clusters in this paper is considered as the main target and the model basis of the impulse strategy. This is due to the fact that local clusters create an immediate living environment for a city dweller, and provide evaluation material for determining the quality of all urban formation.

The first of these is the techno-biospheric symbiosis (Fig. 1), which is characteristic of the historic city regarding the development of a culture of re-evaluation of already existing urban structures. In the present conditions, it includes only material hand-made objects - buildings, small forms (fountains, monuments, paving, etc.), cityplanning relics (existing network of streets, ports, industrial zones, concentric circle of urban fabric development, etc.). Instead, for the re-evaluation of the creation of techno-biospheric symbiosis, it is necessary to supplement the concept of the value of 
the historic environment, and above all, objects of non-artificial nature - namely, the elements of the natural environment, flora and fauna. Here we can distinguish three principal parts of the project activity: decorative, geo-rehabilitation, and transformative.

\section{The anticipated results of a combination of universal and formative factors of impulse development}

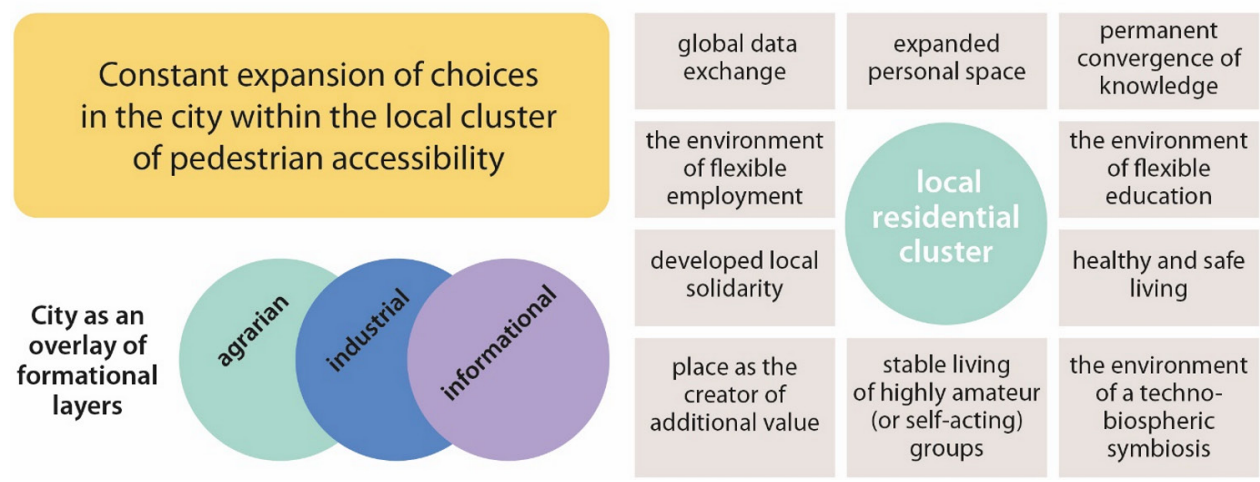

Source: author's study

Fig. 1. Principles of impulse modeling in local clusters of urban structure

Decorative aspect is the simplest, and it does not require any further explanation, as it is about the development and design as well as administrative support of traditional types of landscaping, both private and communal (greening of window sills, lawns, small open spaces, elements of vegetation cover, etc.).

Geo-rehabilitation aspect requires a more complex set of measures for the restoration of authentic elements of the natural space - springs, streams, rocks, elements of distorted relief, rain water (interior-yard space), fresh fruit markets (Fig. 2).

Transformative aspect, at this stage, can be viewed more in the design-experimental perspective. It envisages the most profound transformation of the existing environment by the very elements of this environment. With this type of transformation, there should be a possibility of radical change in their functional scheme (greening of interiors and interior spaces of buildings), changes in visual perception of buildings (location of large landscape elements in the immediate vicinity of valuable buildings), transformation of certain parts of buildings to meet the needs of micro-landscaping complexes (replacement of existing roofs with the containers suitable for the planting of trees, greening of pedestrian streets, disma ntling some internal parts of buildings or quarters in order to accommodate biospheric squares, etc.). Although the latter part is defined here as a design-experimental one, it is precisely in this area that the greatest 
potential of impulse modeling lies. This is due to the general crisis in the downtowns of historical cities, which, in turn, due to the saturation of tourism and business infrastructure, became less attractive for permanent residence. In addition, historical, and first of all, pre-modern-day housing in terms of quality and comfort of residence is often inferior to the modern one, and in terms of personal space, it is considerably inferior to suburban housing. In this sense, the transformative aspect of the technobiospheric symbiosis (in combination with the other two) can serve as a significant resource for the revitalization of historical regions, the return of permanent residents thereto, and the restoration of functional integrity to the entire urban organism (Fig. 3).

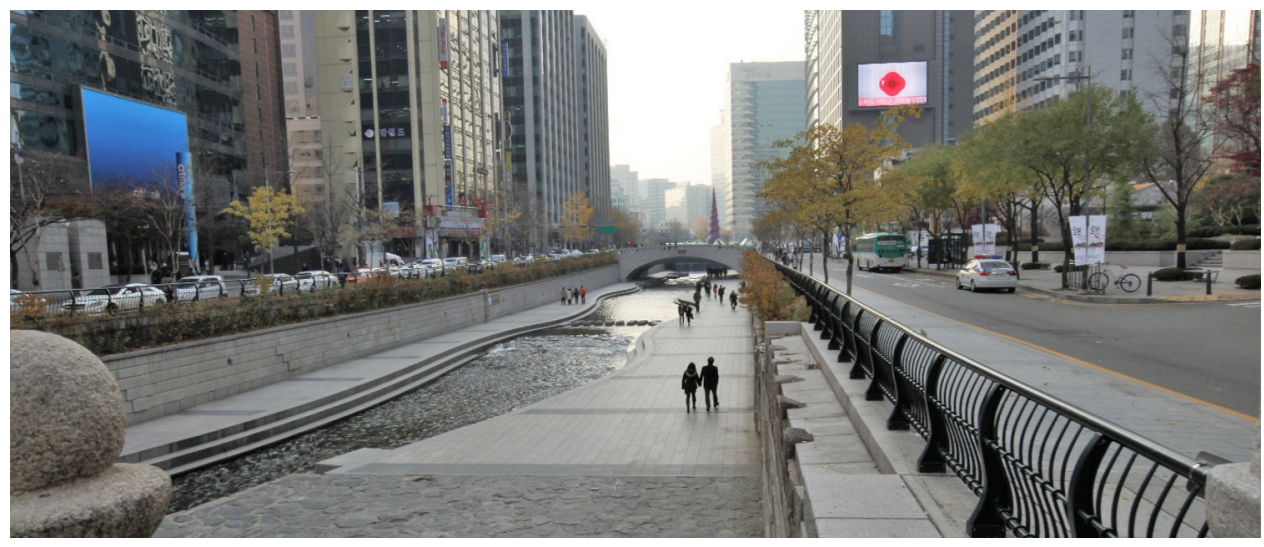

Fig. 2. Regeneration of the previously concrete-covered Cheonggyecheon rive (photo by A. Pavliv, 2012)
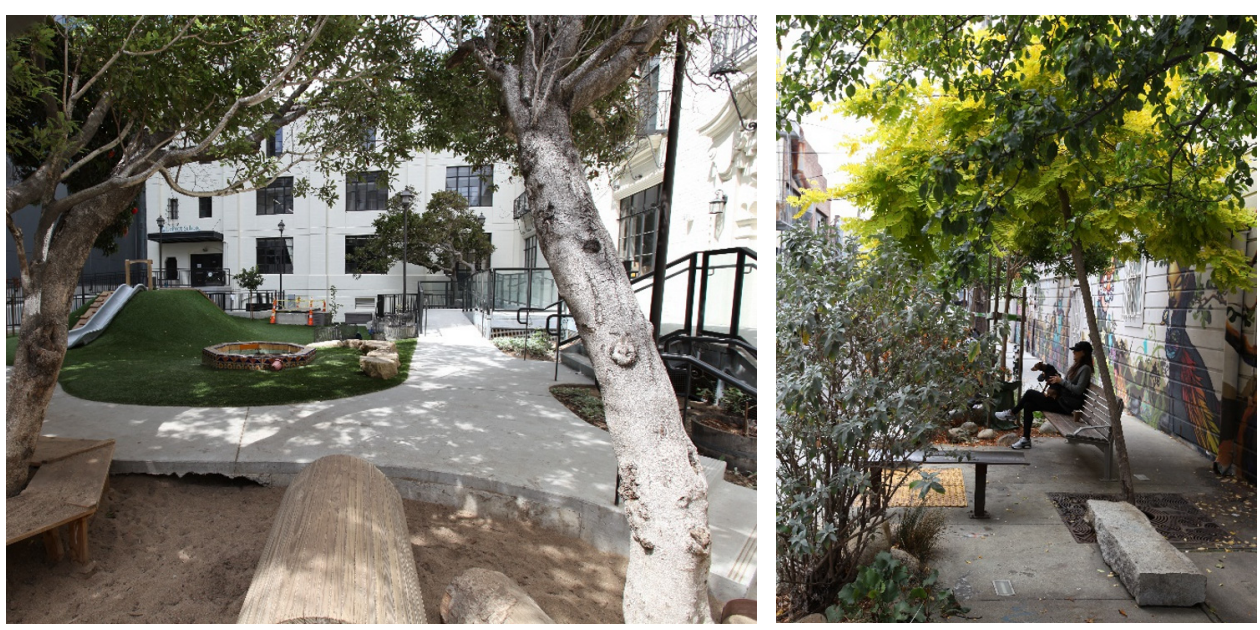

Fig. 3. Refurbishment of the courtyard, and street greening in the historic district of San Francisco (photos by A. Pavliv, 2016) 
The recommendations described above relate primarily to the areas of historically valuable development, where the possibilities of impulse interference, followed by self-transformation of the surrounding area, are the most limited. However, in a postindustrial city, such areas tend to account for only a small fraction of its territory, most of which is open to a much wider range of changes. The strategy of high density and techno-biospheric symbiosis suggests that such a symbiosis can be realized only in the perspective of three-dimensional space, which involves multi-level landscaping and greening, including vertical parks and their combination with high-rise residential buildings on the level of higher floors.

It is obvious that within the same level there are also more general parameters of the techno-biospheric symbiosis - such as pedestrian accessibility, noise reduction, an effective system of combating harmful waste and emissions, and so forth.

Also, in the development of a residential local cluster of a post-industrial city, the factor of the accumulation of global presence plays a leading role. In fact, its content is the process of gradual blurring and, ideally, the disappearance of the notion of periphery as the category of the mental frame of the city's inhabitants. The nature of the globalized flow of information, intermediaries of which are various technological agents, makes it possible to interpret each space of universal pedestrian accessibility as a hub of global presence.

A key requirement of post-industrial urbanism, for any city in the 21st century, is the category of living space with a wide choice. Obviously, in essence, this option also has an individual character, as it concerns each and every citizen, and therefore its featuring relates to that urban planning concept, which is defined here as a local urban planning cluster.

The theoretical ideal of a maximum choice at the minimum transport cost possible (pedestrian access) and its individual targeting limit the range of design hypothesis to a conventional circle with the diameter of two kilometres, which must be filled with the mixed-use urban fabric, with dense infrastructure, mainly of residential function. The first determinant of the living space of a wide choice, which is theoretically proposed in this paper, is the multi-landscape area (Fig. 4).
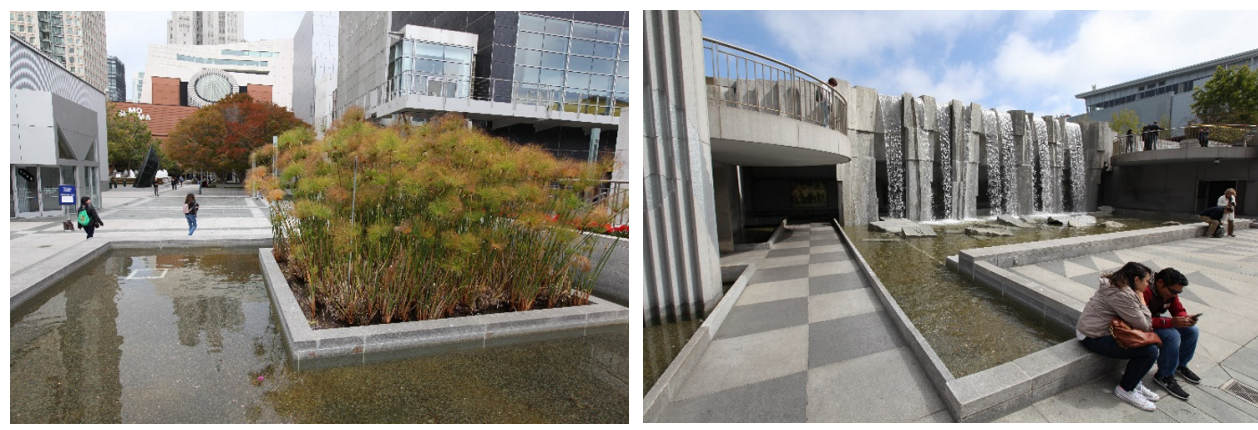

Fig. 4. San Francisco. An example of the organization of a landmorph, multi- landscape space (photos by A. Pavliv, 2016) 
Previously, this particular quality took the form of using the already existing properties of the land relief and land development for urban planning purposes. In addition, in these cases, the contrast between the scale of the cluster and natural forms (mountain ranges, water bodies, alternation of favourable and not favourable features for resettlement of plots) was preserved. This contrast was partly harmonized by stretching of urban and especially residential structures, which, therefore, either lost the advantages of compactness (such as pedestrian / bike accessibility), or began lacking optimal density, acquiring some features of a low- density rural settlement. From this point of view, creation of a multi-landscape area appears as a problem of artificial disassembly of a geomorphic selection. Although such task, in itself, can be considered a pioneering one, certain manifestations of design decisions related to its elaboration can be found in the economically developed ancient cultures, as well as in the current quest for micro-landscaping in urban living space (Fig. 5). In the first case, we are talking about large city-wide public complexes (such as thermal baths or hanging gardens), and in the second case, about landmorphs, nature-morphs and bioclimatic structures, integrated into a dense urban space (the skyscraper of Kommerzbank in Frankfurt, the educational hub of the School of Art, Design and Media University of Nanyang, Technology University in Singapore, Health Sciences Education Building, The University of Arizona, and so forth).

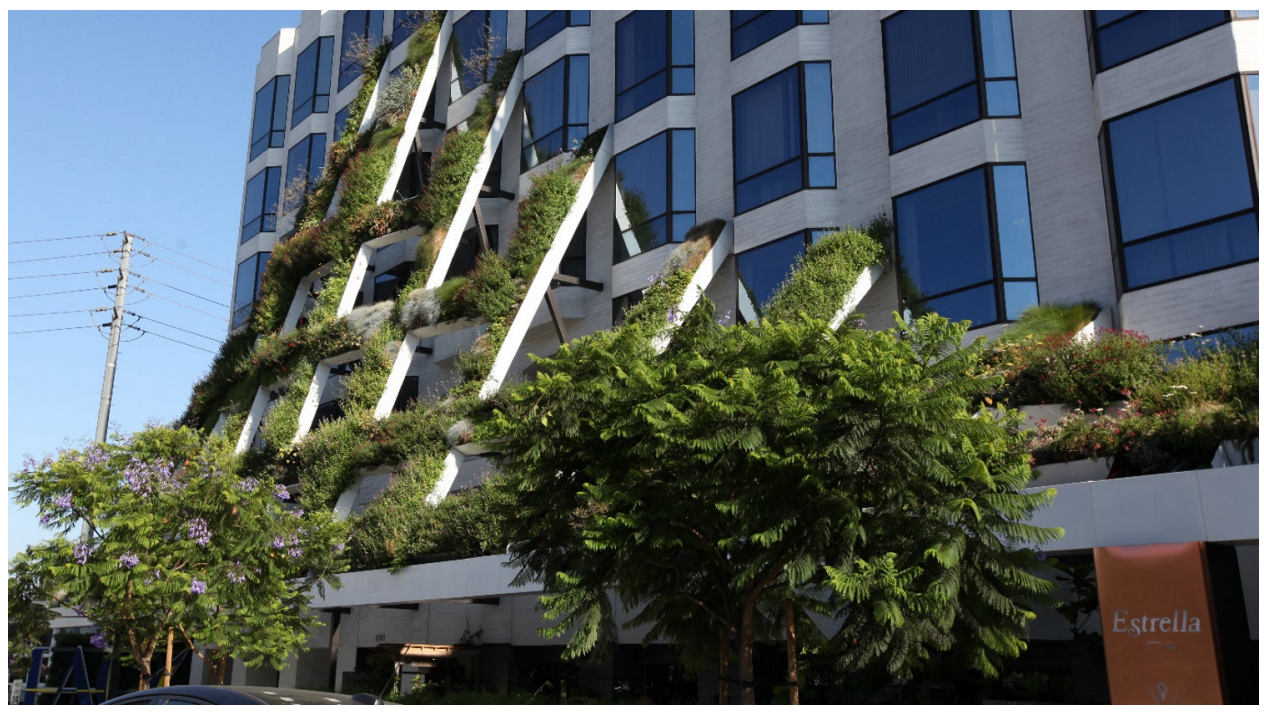

Fig. 5. Los Angeles. Office building. Vertical gardens (photo by A. Pavliv, 2016)

The next component of a local cluster is a different kind of residential settlement. It is based on the process of returning residents who belong to the so-called middle 
class, to the central and middle-central areas of cities, in connection with the increase in the load of transport infrastructure. This return, however, is the reason for updating the new requirements for dense urban development, which we expect to have the same characteristics and conditions that these inhabitants were used to when living in the suburbs (personal green space, more residential and auxiliary premises, no noise or pollution). Thus, high-density urban development was faced with the challenge of "subrubing" features.

It is worth noting, however, that the return to the central regions of the city by representatives of the middle class is only the catalyst for a wider phenomenon of population of various age structure returning to the central parts of the city. Even at the times of the greatest popularity and prosperity of suburbs, the younger generation continued to strive to live in middle-sized areas, close to the infrastructure of dynamic leisure, education and temporary work. Relocation to the suburbs took place mainly only after the birth of children and attaining a certain level of material well-being.

The restoration of age diversity and, as a consequence, fragmentation of the requirements for housing, have led to the need for a variety of resettlement within a pedestrian cluster (such as False Creek area, Vancouver) or optimized quarterly development areas ("Barcelona Quarter").

In the context of considering the problems of constructing impulse factors that would shape the living space of a wide choice at the level of the local cluster with pedestrian accessibility, a special place is occupied by the task, which is outlined as an education of a different experience.

The traditional system of education that arose in the era of post-agrarian industrial societies was characterized by age and levelled determinism. Educational centers were divided into different levels, the lower of which (primary and secondary schools) were built into the pedestrian zone of individual living space, while others (specialized schools and universities) often required a radical change of residence and lifestyle, relocation to another city, and the rupture of complex family and social ties. In addition, education was a matter solely for the first half (or perhaps third) of life, which determined its further character and sectoral content. The context of the information society, for which the rapid change of the actual knowledge and models of economic interaction between different subjects is characteristic, has significantly changed the educational model. Now it has received some new, remote and interactive methodologies for sharing information and more flexible age segmentation. The growth of creative and intellectual employment, "craft" production, the rapid appearance and disappearance of occupations, which is accompanied by oversaturation of the informational space by unreliable and unstructured information, leads to the idea of the need to transfer permanent post-industrial education from large institutional centers to a more close living space of the local cluster.

Methods of implementing a new educational paradigm at such level are unlikely to be related to the traditional stereotype of a specific institution constructed especially for educational functions (a typologically separate building, designed in accordance with specially developed norms). The future of a new, flexible education is more likely 
to lie within the larger complexes of presence - shopping and entertainment, leisure centers, theme parks, micro-landscape zones, and so forth. Thus, new forms of flexible education may appear within the scope of the pedestrian zone of the cluster, just as preschool institutions and schools used to be in the framework of the micro-district planning paradigm. To a certain extent, this view also supports the transformation of the teaching methodology, which increasingly incorporates elements of games and intellectual leisure.

To a large extent, such a model of "education" in local clusters is difficult to imagine as a practical reality. However, there are certain factors, which testify in favour of this approach:

a) Creation of virtual and distance learning courses, affiliates and regional clusters by well-known univerisities;

b) The ability of some individuals in a rich information environment to independently accumulate and interpret a certain amount of knowledge, to experience and share it with the others.

The transformation of education from a state-run, vertically integrated, static institution into a creative and commercial form of leisure, opens considerably new and new opportunities for its existence within the local living spaces of urban areas. In this case, impulsive initiatives may occur as spontaneous educational projects - individual initiatives, or propjects conceived as a development of a leisure function and a feature of public presence that transform the pedestrian community into space of coworking collaboration, the results of which display the characteristics of educational products.

For implementation of the impulse strategy at the level of neighbouring groups of pedestrian clusters, the leading role is played by the format and structure of employment, whose parameters have undergone significant changes over the last few decades, which to some extent has confirmed the predictions of the first post-industrialist visionaries [Toffler 2000]. The reduction of working time and staying in specially organized workplaces had its consequence in virtually returning work to a personal living space. In post-Soviet countries, which experienced a long economic recession, this was often opposite to the trend of domestication of employment. In this regard, the processes of reducing the time spent in offices and at workplace led to their transfer not only to the apartment, but also to various places of presence associated with some or other forms of leisure. Parks, quays, cafes, terraces, halls, transformed into a place of work with portable electronic devices and communicators, as new intermediaries of intellectual and creative work of the information-rich society.

After considering the components of the living space of a wide choice, it is worthwhile to pause and take a final view of the urban solution of a local cluster formed by modelling impulse factors. This is a territory with a diameter of up to two kilometers, with the number of inhabitants between 5,000 and 10,000 (the biggest possible number). Taking into account high-density indicators, the building structures of mixed type (and different levels) dominate in such area, with a significant presence of high-rise buildings. The spatial organization of buildings is a set of structural elements, the main characteristic 
of which is as a techno-biospheric symbiosis and the overlapping of privacy zones with areas of public presence, having a character of highly mixed functionality.

The validity of such a potential is partly evidenced, for example, by the studies of Edward Glaeser, and outlined in his monograph "The Triumph of the City" [Glaeser 2011]. In the book, the author cites statistics, which prove large cities, due to man-made factors, to be the best places for human life, providing the highest possible levels (as of today) of health, environment, and wealth. In particular, evidence suggests that New York life expectancy is the longest among all Americans, and the number of critical diseases is lower than in the country as a whole.

However, while Glaeser talks about a large city in general, in our case we focus on its basic structural unit, in which all of the advantages of the city as a whole should be concentrated and present. By means of a combination of horizontal neighbouring initiatives and administrative institutions, the formation of techno-biospheric symbiosis happens here, part of which is not only various ways of greening and rehabilitation of the environment, but also changing forms of the presence of global knowledge. Such features, on the one hand, neutralize the state of periphery, the lack of which is one of the main features of a developed city, and on the other hand, they provide residents with a certain amount of knowledge necessary for the effective adjustment of their own employment, also connected with their own home and the surrounding pedestrian space saturated with zones of a temporary distance job.

At the same time, the local residential cluster receives additional developmental levers by virtue of belonging to an environment of exceptional presence connected with the legendary nature of the city as a whole, unique events of the past and present that confirm its status of a unique part of global life. The city provides particularly favorable conditions for the development of certain sectors of different activities related to the social and natural features that are formed there, and it contributes to the permanent residence of highly amateur (or self-acting) groups of population. The social balance between the economically successful parts of society (the "creative class") and the others is achieved through the promotion and validation of post-economic activities ("economy of happiness", Richard A. Easterlin).

\section{Conclusion}

We have outlined the range of practical issues related to the concept of a local cluster and the category of optimal density as the key indicators of the 21 st century city.

We have noted the boundary and desirable indicators of optimum density and spatial models of its features.

It was found that for the conditions of a post-industrial city, the design of the impulse model should consist of two stages: city-wide, and related to the given local cluster.

It is proposed to consider the active development of the local cluster and the "creative class" in post-economic activity as a mechanism for avoiding contrast and potential tension between social and professional groups in the post-industrial society, which is one of the problems of urbanism in the 21 st century. 


\section{References}

Bramley G., Power S. 2009. Urban form and social sustainability: The role of density and housing type. Environ. Plan. B: Plan. Design, 36(1), 30-48.

Cherkes B.S. 1992. Horod y ahrarnaia sreda. Svit, Lviv, 150.

Gandelsonas M. 1999. X-Urbanism: Architecture and the American City. Princeton Architectural Press, New York.

Glaeser E., Edward L. 2011. Triumph of the city: How our greatest invention makes us richer, smarter, greener, healthier, and happier, Penguin Books.

Hall P. 2005. Urban and Regional Planning (4th ed.). Routledge, London and New York Press, New York.

Koolhaas R., Mau B. 1995. S, M, L, XL. Monacelli Press, New York.

Kostof S. 1999. The City Shaped: Urban Patterns and Meaning through History (2nd ed.). Thames \& Hudson, New York-London.

Neuman M. 2005. The Compact City Fallacy. J. Plan. Educ. Res., 25, 11-26.

Register R. 1987. Eco-City Berkeley: Building Cities for a Healthy Future. North Atlantic Books. Sverdlin L. 2004. Peshehodnaya dostupnost ostanovok obschestvennogo transporta.

Metodicheskiy aspekt: http://waksman.ru/Russian/Economics/Sverdl_04.htm (accessed: 15.07.2018).

Toffler E. 2000. Tretia khvylia. Vydavnychyi dim "Vsesvit", Kyiv.

Ph.D., Andriy Pavliv

Lviv Polytechnic National University

Department of Design and Basic Architecture

79013 Lviv, S. Bandery str. 12

email: andrii.p.pavliv@lpnu.ua 